\title{
ALIH KODE DAN CAMPUR KODE DALAM TUTURAN MASYARAKAT GAMPONG MATANG SEULIMENG KOTA LANGSA
}

\author{
Rudi $^{*}$ \\ Muhammad Yakob ${ }^{2}$ \\ Desy Irafadillah Effendi ${ }^{3}$ \\ ${ }^{1}$ Program Studi Bahasa Indonesia, FKIP Universitas Samudra \\ ${ }^{2}$ Program Studi Bahasa Indonesia, FKIP Universitas Samudra \\ ${ }^{1}$ Program Studi Bahasa Indonesia, FKIP Universitas Samudra \\ *rudi05081997@gmail.com
}

\begin{abstract}
This research is entitled " code-switching and code-mixing in the speech of the people of mature village, seulimeng, Langsa City”. The formulation of the problem in this research is how is code switching and code mixing in the speech of the people of Gampong Matang Seulimeng Langsa city. This study also aims to describe code switching and code mixing on the speech of the people of Gampong Matang Seulimeng Langsa city. Data collection techniques used observation techniques, recording techniques, listening techniques and note taking techniques. Data analysis was carried out descriptively interpretive. Interpretive descriptive method os a method that describes or tells about the views or opinions of the object under study. The result of the study show that there are eight code switching data and ten code mixing data.from this data it can be seen that the people of Gampong Matang Seulimeng use code switching and code mixing in communicating.
\end{abstract}

Keywords:

Code Switching, Code Mixing, Speech Society, Langsa

\begin{abstract}
Abstrak
Penelitian ini berjudul "Alih Kode Dan Campur Kode Dalam Tuturan Masyarakat Gampong Matang Seulimeng Kota Langsa." Rumusan masalah dalam penelitian ini adalah bagaimanakah alih kode dan campur kode dalam tuturan Masyarakat Gampong Matang Seulimeng Kota Langsa. Penelitian ini juga bertujuan untuk mendeskripsikan alih kode dan campur kode dalam tuturan Masyarakat Gampong Matang Seulimeng Kota Langsa. Teknik pengumpulan data menggunakan teknik observasi, teknik rekam, teknik simak, dan teknik catat. analisis data menggunakan metode deskriptif kualitatif. Analisis data dilakukan secara deskriptif interpretatif. Metode deskriptif interpretatif yaitu metode yang mendeskripsikan atau menceritakan mengenai pandangan atau pendapat dari objek yang diteliti. Hasil dari penelitian menunjukkan bahasa terdapat 8 data alih kode dan terdapat juga 10 data campur kode. Dari data tersebut dapat diketahui bahwa masyarakat Gampong Matang Seulimeng menggunakan alih kode dan campur kode dalam berkomunikasi.
\end{abstract}

Kata Kunci:

Alih Kode, Campur Kode, Tuturan, Masyarakat Langsa 


\section{Pendahuluan}

Masyarakat yang multibahasa muncul karena masyarakat tutur tersebut mempunyai atau menguasai lebih dari satu variasi bahasa yang berbeda-beda sehingga mereka dapat menggunakan pilihan bahasa tersebut dalam kegiatan berkomunikasi. Menurut KBBI (2017: 148) bahasa merupakan sistem lambang bunyi yang arbitrer, yang digunakan oleh anggota suatu masyarakat untuk bekerja sama, berinteraksi, dan mengidentifikasikan diri. Jadi dapat disimpulkan bahwa bahasa merupakan sistem lambang bunyi ujaran yang digunakan masyarakat untuk berkomunikasi dan berinteraksi dengan masyarakat lainnya, baik untuk bertukar informasi, menyampaikan gagasan atau ide, mengungkapkan perasaan, keinginan, dan lain sebagainya.

Bahasa merupakan alat komunikasi yang sering digunakan oleh manusia untuk menunjukkan identitas masyarakat pemakainya. Komunikasi merupakan sesuatu hal yang sangat penting bagi terbentuknya suatu kelompok dan masyarakat. Chaer dan Agustin (2017: 154) menyatakan bahwa di Indonesia pada umumnya menggunakan 3 bahasa, yaitu: bahasa Indonesia, bahasa daerah, dan bahasa asing. Kemampuan menguasai bahasa pertama dan bahasa kedua ini membuat masyarakat yang multilingual yang artinya masyarakat yang menguasai lebih dari dua bahasa.

Sosiolinguistik adalah bidang ilmu antar disiplin yang mempelajari bahasa dalam kaitannya dengan penggunaan bahasa itu di dalam masyarakat (Chaer, 2004: 2). Bahasa sebagai objek dalam sosiolinguistik tidak dilihat atau didekati sebagai bahasa, melainkan dilihat sebagai sarana interaksi atau komunikasi di dalam masyarakat.

Alih kode adalah peristiwa bahasa atau ragam bahasa oleh penutur karena adanya sebabsebab tertentu yang dilakukan dengan sadar (Chaer dan Agustina, 2010: 107). Alih kode merupakan suatu gejala yang menyebabkan terjadi suatu perpindahan atau peralihan suatu bahasa yang disebabkan karena perubahan situasi dan kondisi (Marni, 2016: 2). Alih kode adalah peristiwa peralihan dari satu kode ke kode lain misalnya penutur menggunakan bahasa Indonesia alih-alih menggunakan bahasa Aceh. Dalam masyarakat multibahasa sangat sulit penutur disetujui hanya menggunakan satu bahasa.

Campur kode merupakan peristiwa tutur yang melibatkan dua orang yang menggunakan dua bahasa seperti bahasa Indonesia dan bahasa Aceh, dan dalam berbahasa ia menggunakan bahasa Indonesia namun seketika itu pula ia berpindah bahasa. Penggunaan lebih dari satu bahasa dan pengalihan suatu percakapan bukanlah suatu hal yang baru di dengar atau sesuatu hal yang asing sebab Indonesia adalah negara yang kaya akan keberagaman bahasa daerah dan suku termasuk di Kota Langsa bagian Gampong Matang Seulimeng. Di gampong ini terdapat banyak bahasa daerah karena banyaknya penduduk yang pindah atau transmigrasi sehingga menyebabkan bahasa Aceh tak lagi menjadi bahasa yang utama. Dari keberagaman bahasa ini pula timbulnya alih kode dan campur kode yang terjadi disebabkan karena bahasa daerah yang berbeda-beda. Demi terjadinya suatu komunikasi maka alih kode dan campur kode harus ada.

Hal ini menyebabkan peneliti ingin melakukan suatu penelitian tentang alih kode dan campur kode yang terjadi pada Masyarakat Gampong Matang Seulimeng. Adapun alasan peneliti mengambil alih kode dan campur kode di Gampong Matang Seulimeng, yaitu: (1) Masyarakat sering berkomunikasi menggunakan bahasa Aceh, bahasa daerah lainnya dan bahasa Indonesia. (2) Masyarakat menggunakan bahasa yang lebih dari satu bahasa ketika berinteraksi sesama masyrakat lainnya. (3) Masyarakat tidak hanya berasal dari Kota Langsa saja, melainkan dari daerah lainnya. (4) Karakteristik atau ciri khas kata atau bahasa yang digunakan memiliki keunikan tersendiri sehingga menarik untuk diteliti.

Beberapa penelitian yang relevan dengan penelitian ini adalah penelitian Irsyad Afriyanto (2007) berjudul "Analisis Alih Kode dan Campur Kode dalam Pemakaian 
Bahasa Indonesia pada Pementasan" Kolot "Karya W.S. Rendra yang diperankan kelompok Peron Surakarta. Hasil temuan menunjukkan bahwa alih kode dalam pemakaian bahasa Indonesia pada penelitian Irsyad terdapat alih kode eksteren yang ditandai dengan adanya peralihan bahasa asing ke bahasa Indonesia dan sebaliknya. Wujud campur kodenya meliputi campur kode interen yang ditandai adanya unsur yang berasal dari bahasa Indonesia yang serumpun yaitu bahasa Indonesia dan bahasa Jawa yang berupa campur kode yang berwujud kata dan campur kode yang berwujud frasa. Adapaun wujud campur kode yang ditandai adanya unsur yang berasal dari bahasa Asing yaitu bahasa Inggris dan bahasa Cina ke dalam bahasa Indonesia, wujud campur kode yaitu campur kode berwujud kata, frasa, perulangan kata, dan klausa.

Selaras penelitian Lina Puspita Ningrum (2009) berjudul "Alih Kode dan Campur Kode dalam Pembelajaran Bahasa Indonesia Kelas II SD Negeri Selopukang, Kecamatan Wonogiri Kabupaten Wonogiri". Hasil temuan menunjukkan bentuk alih kode yang terjadi barupa alih kode interen, yaitu peralihan bahasa Indonesia ke bahasa Jawa atau sebaliknya. Bentuk campur kode yang terjadi dalam pembelaran bahasa Indonesia kelas II SD Negeri Selopukang, berupa campur kode kata, campur kode frasa, dan campur kode klausa. Campur kode tersebut di lakukan oleh guru, karena guru mengetahui pemahaman kosa kata yang dimiliki oleh peserta didik masih rendah. Campur kode yang dilakukan oleh guru tersebut dilakukan tanpa disadari.

\section{Metodologi Penelitian}

Pendekatan yang digunakan dalam penelitian ini adalah pendekatan kualitatif. Menurut Bodgan dan Biklen, S (dalam jurnal Rahmat, 2009: 2), menjelaskan bahwa penelitian kualitatif adalah salah satu prosedur penelitian yang menghasilkan data deskriptif berupa ucapan atau tulisan perilaku orangorang yang diamati. Pendekatan kualitatif diharapkan mampu menghasilkan uraian yang mendalam tentang ucapan, tulisan, dan atau perilaku yang dapat diamati dari suatu individu, kelompok, masyarakat, dan atau organisasi tertentu dalam suatu konteks tertentu.

Penelitian ini berlatar alamiah, maksudnya adalah fenomena kebahasaan yang terjadi secara alamiah dan tidak dimanipulasi, direncanakan, atau dibuat-buat oleh peneliti. Fenomena kebahasaan yang dimaksud yaitu berupa tuturan yang mengandung ragam bahasa. Jenis penelitian yang digunakan adalah metode deskriptif. Metode deskriptif adalah metode untuk menggambarkan atau melukiskan fakta atau gejala-gejala yang tersusun. Metode ini mendeskripsikan alih kode dan campur kode dari penutur asli yaitu para masyarakat secara apa adanya di Gampong Matang Seulimeng Kota Langsa tanpa adanya rekayasa baik dari pihak peneliti maupun yang diteliti. Sumber data dalam penelitian ini adalah masyarakat Gampong Matang Seulimeng Kota Langsa. Data penelitian ini adalah alih kode dan campur kode yang terdapat dalam tuturan lisan masyarakat Gampong Matang Seulimeng Kota Langsa yang berusia 17-50 tahun. Pada penelitian ini, analisi data dilakukan dengan menggunkan analisis deskriptif kualitatif. Peneliti menggunakan metode simak, catat, dan rekam karna peneliti mendengar, menyimak dan merekam percakapan secara langsung dari informan.

\section{Hasil dan Pembahasan}

Dalam kehidupan sehari-hari, masyarakat tidak lepas dari penggunaan bahasa. Bahasa yang digunakan oleh masyarakat di Gampong Matang Seulimeng, Kota Langsa menggunakan bahasa yang beragam yang disebabkan oleh adanya alih kode dan campur kode dalam percakapan. Alih kode yang terdapat di kampung ini yaitu alih kode dari bahasa Indonesia ke bahasa Aceh dan alih kode dari bahasa Aceh ke bahasa Indonesia dan ke bahasa daerah lainnya. Sementara campur kode yang terdapat pada masyarakat yaitu campur kode bahasa Indonesia, bahasa Aceh, bahasa Jawa, dan bahasa asing. 
Masyarakat yang multibahasa muncul karena masyarakat tutur tersebut mempunyai atau menguasai lebih dari satu varian bahasa yang

$\begin{array}{cc}\text { Pembeli } 1 & \text { : "Campli padum sie } \\ & \text { on?" } \\ & \text { 'Cabai brapa satu } \\ \text { ons?' } & \\ \text { Pedagang } & \text { : "Campli dua ribe } \\ & \text { sitengeh sie on" } \\ & \text { 'Cabai dua ribu } \\ \text { setengah satu ons' }\end{array}$

Pembeli 2 : "Bawang merah
brapa"

Pedagang $\quad$ "Empat ribu
seperampat"

Pedagang : : Apalagi?”

Pembeli 2 : "Cabe ijo"

Pedagang : "Brapa"

Pembeli 2 : “1000”

berbeda-beda. Sehingga mereka dapat menggunakan pilihan bahasa tersebut dalam kegiatan komunikasi. Varian bahasa yang terdapat pada masyarakat Matang Seulimeng Kota Langsa yaitu (1) Alih kode dan (2) Campur kode. Dari penelitian yang dilakukan, peneliti mengambil delapan belas data dari segi alih kode dan campur kode. Data tersebut ada yang menggunakan bahasa Aceh bahasa Jawa dan bahasa Indonesia. Seperti salah satu data yang diperoleh yaitu pada data (1) yang menggunakan bahasa Aceh dan juga bahasa Indonesia.

Alih kode dan campur kode yang terjadi di masyarakat Gampong Matang Seulimeng, Kota Langsa karena adanya situasi berbahasa yang beragam, penutur yang heterogen, tidak adanya padanan kosakata dalam satu bahasa, kebiasaan, dan juga agar terlihat lebih gaul oleh lawan tuturnya sehingga terjadilah alih kode dan campur kode tersebut. Adapun hasil penelitian yang telah dilakukan dapat dilihat pada pembahasan yang akan penulis uraikan pada uraian berikut ini.

\section{Alih Kode}

Menurut Appel (dalam Chaer dan Agustina, 2004: 141) alih kode adalah gejala yang peralihan pemakaian bahasa karena berubah situasi. Berbeda dengan Appel yang mengatakan alih kode itu terjadi antar bahasa, maka Hymes (dalam Chaer dan Agustina, 2004: 142) mengatakan alih kode itu merupakan gejala peralihan pemakaian bahasa yang terjadi karena situasi dan terjadi antar bahasa serta antar ragam dalam satu bahasa. Berikut datanya.

Data 1

1) Waktu

: Senin, 19 Oktober 2020

Pukul : 09.00 WIB s.d. 09.35

WIB

Tempat : Lingkungan I

Nama Informan

$$
\text { : Eva }
$$

Alih kode yang terdapat pada data (1) yaitu berupa alih kode dari bahasa Aceh ke bahasa Indonesia. Alih kode dari bahasa Aceh ke bahasa Indonesia yaitu ketika pembeli 1 bertanya kepada pedagang "campli padup sie on?" kepada pedagang, kemudian pedagang menjawab dengan mengatakan bahwa : "Campli dua ribe sitengeh sie on" dengan menggunakan bahasa Aceh, setelah itu pembeli 3 datang dan bertanya berapa harga bawang, kemudian pedagang menjawab dengan mengatakan bahwa harga bawang adalah empat ribu seperempat dengan menggunakan bahasa Indonesia. Dalam situasi berbahasa tersebut ketika pembeli 1 dan pedagang berinteraksi dengan menggunakan bahasa Aceh, dan ketika pembeli 3 datang menggunakan bahasa Indonesia pedagang menjawab menggunakan bahasa Indonesia. Sehingga dalam situasi tersebut terjadilah alih kode yaitu dari bahasa Aceh ke bahasa Indonesia. Hal tersebut terjadi karena hadirnya pihak lain dalam situasi berbahasa, pihak tersebut yaitu pembeli 3 yang bukan merupakan penutur bahasa Aceh sehingga pedagang menggunakan bahasa Indonesia untuk 
melayani pembeli agar komunikasi berjalan lancar.

Data 2

2) Waktu Desember 2020

$\begin{array}{ll}\text { Pukul } & : \text { 22.00-22.20 WIB } \\ \text { Tempat } & \text { : Lingkungan 1 } \\ \text { Nama Informan } & \text { : Tuti }\end{array}$

$\mathrm{Tt}$ : "Kue kie harinie ngopoie pangana opo?" ('Kamu hari ini masak, makan apa?')

Ai : "Tadi makanannya cuman pakek nasik"

Tt : "Pangane, panganane nasik aeee, lauk eee?"'Makannya makan nasi, lauknya apa?'

Alih kode yang terdapat pada data (2) yaitu berupa alih kode dari bahasa Jawa ke bahasa Indonesia. Pada data ini ketika $\mathrm{Bu}$ Tuti bertanya kepada $\mathrm{Bu}$ Ani dengan mengatakan "Kue kie harinie ngopoie panganan opo?" yang artinya kamu hari ini masak, makan apa? Dengan menggunakan bahasa Jawa, lalu $\mathrm{Bu}$ Ani menjawab dengan menggunakan bahasa Indonesia dengan mengatakan bahwa ia tadi hanya makan pakai nasi. Keadaan tersebut berlangsung antara komunikasi $\mathrm{Bu}$ Tuti dan $\mathrm{Bu}$ Ani yaitu $\mathrm{Bu}$ Tuti tetap menggunakan bahasa Jawa dalam beberapa pertanyaannya dan $\mathrm{Bu}$ Ani tetap menggunakan bahasa Indonesia dalam tuturannya. Sehingga terjadi alih kode dalam peristiwa tutur tersebut. Hal tersebut terjadi karena kedua penutur saling mengerti terhadap bahasa yang digunakan atau bisa dikatakan memiliki latar belakang bahasa yang sama. Bu Ani menggunakan bahasa Indonesia walau $\mathrm{Bu}$ Tuti sudah menggunakan bahasa Jawa karena dalam pengucapan bahasa Jawa bu Ani tidak bisa, namun mengerti dengan bahasa Jawa.

Data 3

3) Waktu : Senin, 19 Oktober 2020

Pukul : 09.00 WIB s.d. 09.35

WIB

Tempat

: Lingkungan I
Nama Informan : Eva

$\begin{array}{ll}\text { Pedagang } & \text { : "Lom" } \\ & \text { 'Lagi?' } \\ \text { Pembeli I } & \text { : "Peu lom" } \\ & \text { 'Apalagi' }\end{array}$

Pedagang : "Minyak sama tomat"

Pembeli 1 : "Nebrie nyoe me seribe tek"

'Kasih ini seribu lagi'

Pedagang : : 3, 2000 lagi”

Alih kode yang terdapat pada data tersebut yaitu berupa alih kode dari bahasa Aceh ke bahasa Indonesia. Saat pembeli bertanya kepada diri sendiri dan mengatakan "pue lom?" menggunakan bahasa Aceh yang berarti apalagi?, pedagang menjawab dengan menggunakan bahasa Indonesia dan mengatakan "minyak sama tomat" sehingga terjadi alih kode dalam peristiwa tutur tersebut. hal tersebut terjadi akibat tidak adanya padanan bahasa dalam salah satu kata yang ingin diutarakan yaitu tomat, sehingga pedagang langsung mengatakan minyak sama tomat.

Data 4

4) Hari / Tanggal : Senin, 10 Oktober 2020

Pukul

: 21.00 WIB s.d. 21.40

WIB

Tempat

: Lingkungan 3

Nama Informan : Safrizal

Sz : "Kadang-kadang bak ta mimbak"

'Kadang-kadang kalok kita tembak'

$\mathrm{Nz} \quad$ : "Tekepak $l h "$

'Terkejut lah'

Af : "Jangan bob" 
November 2020

$\begin{array}{ll}\text { Pedagang } & \text { : "Beli apa dek?" } \\ \text { Pembeli } 1 & \text { : "Ini!" } \\ \text { Pedagang } & \text { : "Nyoe?" } \\ & \text { 'Ini?' } \\ \text { Pembeli } 1 & \text { : "Inil" } \\ \text { Pedagang } & \begin{array}{l}\text { : "Yang nyoe } \\ \text { siplhoh ribe, nyoe } \\ \text { lheblhah ribe" } \\ \text { 'Yang ini sepuluh } \\ \text { ribu, yang ini } \\ \text { tigablas ribu' }\end{array}\end{array}$

Pembeli 1 : "Ini udah dibelah buk."

$\begin{array}{ccc}\text { Pedagang } & \text { : "Dah dibelah" } \\ \text { Pembeli } 1 & \text { : "Ikan ada bu?" } \\ \text { Pedagang } & \begin{array}{c}\text { : "Cok } \\ \text { manteng" } \\ \text { "Ambel udeng } \\ \text { saja' }\end{array}\end{array}$

Pembeli 1 : "Haek, yang ini berapa nie?"

'Tidak, yang ini berapa nie?'

Pedagang : : "Itu 15 ada."

$\mathrm{Sz} \quad$ : "Meno ee, exxzz... goyang wak nyan"

'Gini ee, exxzz... takut orang itu'

Af : "Purak-purak wewen kah"

'Purak-purak wewen kamu'

Pada percakapan tersebut terjadi alih kode dari bahasa Aceh ke bahasa Indonesia. Saat Nazar dan safrizal berbicara menggunakan bahasa Aceh, Arifin dalam satu percakapan membalas dengan menggunakan bahasa Indonesia dengan mengatakan "jangan bob" walau sebenarnya padanan kata jangan ada dalam bahasa Aceh. Percakapan ini memiliki maksud yaitu $\mathrm{Sz}$ menceritakan tentang pengalaman ia bekerja di Satlantas kepada teman-temannya, mereka saling memahami apa yang disampaikan satu sama lain. Ketika Arifin berbahasa Indonesia Safrizal tetap menggunakan bahasa Aceh untuk berkomunikasi dengan lawan tuturnya, dan Arifin menjawab dengan mencampur dua bahasa dalam tuturannya yaitu bahasa Aceh dan bahasa Indonesia. Hal tersebut terjadi agar suasana percakapan lebih akrab lagi.

Data 5

5) Hari / Tanggal : Sabtu, 24 Oktober 2020

Pukul

: 09.00 WIB s.d. 11.00

WIB

Tempat : Lingkungan 4

Nama Informan : Sittah dan Roni

Data tersebut terdapat alih kode dari bahasa Indonesia ke bahasa Aceh begitupun sebaliknya. Pedagang menggunakan bahasa Aceh dalam percakapan yang berlangsung dan pembeli tetap menjawab dengan menggunakan bahasa Indonesia sehingga terjadilah alih kode dalam peristiwa tutur tersebut. Ketika pedagang bertanya kepada pembeli hendak membeli apa, pembeli menjawab dengan menggunakan bahasa Indonesia "ini" dan pedagang bertanya lagi untuk memastikan bahwa yang dimaksud adalah sama dengan pedagang denga mengatakan "nyoe" yaitu menggunakan bahasa Aceh. Bukan hanya itu, ketika pembeli bertanya apakah ikan ada dengan menggunakan bahasa Indonesia, lalu pedagang kembali menjawab dengan bahasa Aceh dengan mengatakan "Cok udeng manteng"sehingga kembali terjadi alih kode dalam percakapan tersebut. Hal tersebut terjadi karena pedagang dan pembeli saling mengerti dengan kedua bahasa, namun pembeli tidak bisa berbicara dengan 
menggunakan bahasa Indonesia, namun mengerti dengan bahasa tersebut sehingga percakapan tetap berlangsung dengan baik. Pembeli juga ada menggunakan kata haek dalam tuturannya karena kata tersebut merupakan kata yang sering digunakan oleh masyarakat.

Data 6
6) Waktu
: Sabtu, 19
Desember 2020

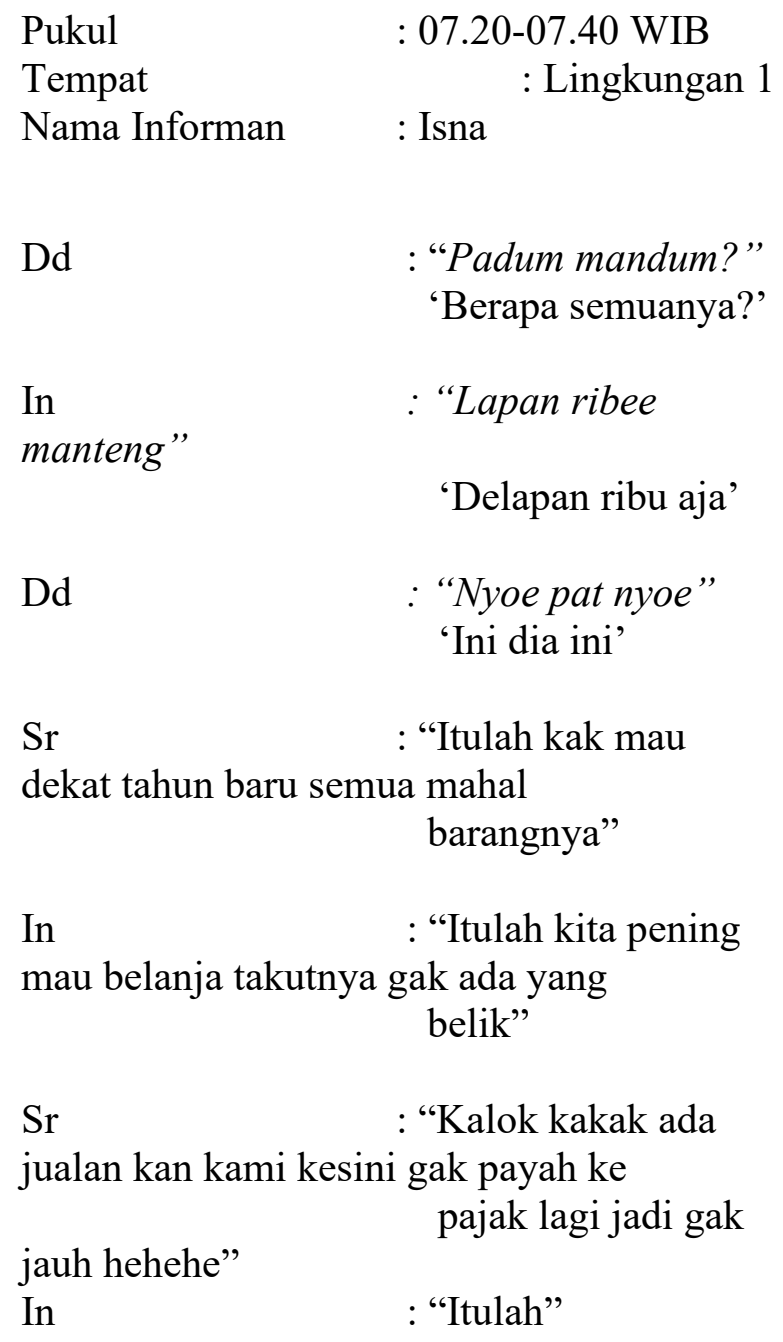

Pada data tersebut terdapat alih kode dari bahasa Aceh ke bahasa Indonesia. Ketika Ibu Dedek yang sedang membeli bertanya kepada penjual berapa semua harga belanjaannya dengan menggunakan bahasa Aceh dan di jawab oleh pedagang menggunakan bahasa Aceh juga. Kemudian Ibu Sari yang juga pembeli berkata "Itulah kita pening mau belanja takutnya gak ada yang belik" karena melihat semua harga belanjaan naik. Ibu Sari berbicara menggunakan bahasa Indonesia walaupun ketika ibu Dedek dan Ibu Isna menggunakan bahasa Aceh saat berbicara, namun ketika Ibu sari menggunakan bahasa Indonesia $\mathrm{Bu}$ Isna selaku penjual berkomunikasi dengan menggunakan bahasa Indonesia juga sehigga terjadilah alih kode dalam peristiwa tutur tersebut.

Data 7

7) Waktu : Minggu, 20 Desember 2020

$\begin{array}{ll}\text { Pukul } & : 07.00-08.00 \text { WIB } \\ \text { Tempat } & \text { : Lingkungan } 2 \\ \text { Nama Informan } & \text { : Sittah }\end{array}$

St

:"Apalagi pak?”

$\mathrm{Pd}$

: "Udah itu aja karna

yang lain udah di belik sama ibuk kemarin nie saya tinggal belik daging aja ke pasar, brapa buk semuanya?"

St : "Cabe merah satu kilo 25.000, terus cabe ijo satu kilo 22.000 , terus bawang merah setengah kilo 12.000 semuanya 59.000 pak."

Pd

kasih roiko aja"

St

: "Ini buk lebihnya

It

ilee"

dulu'

: "Ini pak."

: “Kak boh manok

'Kak telur ayam

St

cok, peu lom"

: “Jeut jeut nyoe yak

ambil, apalagi'

'Iyaa iyaa ini mau di

It : : Ka nyan manteng nyoe pat peng jih beh"

'Udah itu aja ini

uangnya iya' 
November 2020

St

$$
\begin{aligned}
& \text { : "Beh" } \\
& \text { 'Iya' }
\end{aligned}
$$

Pada data ini juga terjadi alih kode dari bahasa Indonesia ke bahasa Aceh. Yaitu ketika Bu Sittah dan Pak Dedi berkomunikasi menggunakan bahasa Indonesia seperti pada percakapan yang telah diuraikan, Bu Intan Datang dengan menggunakan bahasa Aceh dan mengatakan "Kak, bloe boh manok limong ribe" maksdunya yaitu ia ingin membeli telur ayam lima butir, dan Bu Sittah menjawab "siat beh" yang artinya sebentar ya. Sehingga pada situasi tersebut terjadi peristiwa alih kode yaitu ketika Bu Sittah dan Pak Dedi menggunakan bahasa Indonesia, Bu Intan datang ingin membeli dengan menggunakan bahasa Aceh kemudian Ibu Sittah selaku pembeli menjawab dengan menggunakan bahasa Aceh. Penyebab terjadinya alih kode dalam peristiwa ini yaitu karena hadirnya pihak lain dalam situasi berbahasa.

Data 8

8) Waktu Desember 2020

Pukul : 07.00-08.00WIB

Tempat : Lingkungan 2

Nama Informan : : Sittah

Nn : "Mak long yak peugoet peyek, padum sie kilo kak?"

'Mamak saya mau

buat keripik peyek, brapa satu kilo buk?'

St

$\mathrm{Nn}$

lah, nyoe peng jih"

uangnya'

$\mathrm{Pd}$ merah satu kilo, cabe ijo satu kilo, setengah

kilo"

St dua ribee, apa pak yang mana?"

: "Nyoe peng balek jih

$\mathrm{Pd}$ : "Cabe merah satu

kilo!"

St : "Terus pak? Ibuk mana pak biasanya ibuk yang belanja kesini!"”

Pd : "Cabe ijo satu kilo, ibuk dirumah dia lagi sibuk ada mau sampek adeknya dari medan ponaannya liburan ke sini ya jadi saya disuruh belanja"

St : "Hehehe, rame lah pak nantik di rumah bapak"

Pd : : "Itulah udah sampek saudara, bawang merah setengah kilo."

St

: "Iya pak, ikan udah

belik pak?"

$\mathrm{Pd}$

: "Ibuk mintak belik

daging lembu."

St namanya ponaannya sampek."

: "Oalah ialah pak

Alih kode yang terdapat pada data (3) yaitu berupa alih kode dari bahasa Aceh ke bahasa Indonesia. Pada tuturan ini yaitu ketika ibu Nini dan ibu Sittah sedang berkomunikasi melakukan transaksi jual beli dengan menggunakan bahasa Aceh, seperti pada percakapan "pue yak bloe dek?" tanya bu Sitta yang merupakan pedagang kepada bu Nini yang hendak membeli, kemudian $\mathrm{Bu}$ Nini juga menjawab dengan menggunakan bahasa Aceh. Namun, ketika pak Dedi datang dan mengatakan "Buk, beli cabe merah satu kilo, cabe ijo satu kilo, bawang merah setengah kilo", kemudian Bu Sittah yang awalnya menggunakan bahasa Aceh saat 
berkomunikasi dengan $\mathrm{Bu}$ Nini beralih dengan menggunakan bahasa Indonesia untuk berkomunikasi dengan Pak Dedi dengan menjawab "apa Pak? yang mana?." Pada situasi berbahasa tersebut terjadi alih kode dari bahasa Aceh ke Bahasa Indonesia, yaitu ketika $\mathrm{Bu}$ Sittah dan $\mathrm{Bu}$ Nini yang berkomunikasi menggunakan bahasa Aceh, Ketika Pak Dedi datang menggunakan bahasa Indonesia Bu Sittah juga menjawab Pak Dedi dengan menggunakan bahasa Indonesia.

\section{Campur Kode}

Campur kode merupakan peristiwa tutur yang melibatkan dua orang yang menggunakan bahasa seperti bahasa Indonesia dan Jawa, dan dalam berbahasa ia menggunakan bahasa Indonesia namun seketika itu pula ia berpindah bahasa Jawa (Marny, 2016). Sedangkan menurut Rulyadi, dkk (2014) campur kode merupakan suatu keadaan menggunakan satu bahasa atau lebih dengan memasukkan serpihan-serpihan atau unsur bahasa lain tanpa ada sesuatu yang menuntut pencampuran bahasa itu dan dilakukan dalam keadaan santai. Campur kode merupakan gejala pencampuran bahasa yang disebabkan oleh berubahnya suatu situasi. Berikut disajikan datanya.

\section{Data 1}

1) Hari / Tanggal : Senin, 10 Oktober 2020

Pukul

WIB

Tempat

Nama Informan

$$
\text { : Lingkungan } 3
$$$$
\text { : Safrizal }
$$

Af

$$
\begin{aligned}
& \text { : "Gajian ngen bang reja } \\
& \text { ijok?" }
\end{aligned}
$$

'Gajian sama abang Reja dikasih?'

$\mathrm{Sz}$

: "Hahaha.... nyan le kasat jih, pokok jih menye

bengeh kujak ke setengah tujoh ke kujak sampoh- sampoh. Kateduk rukok hinah. Waknyoe bede

tetap iyup bantai ipeduk"

"Hahaha.... Itu sama kasatnya, pokoknya asal pagi pergi saya setengah tujuh saya pergi sapusapu. Udah terdudok rokok disitu. Orang ini beda tetap di bawah bantal di taruk'

\section{Af : "Iyalah"}

Sz : :Tetap iminyub bantal, ike adak na pih hana ta sentuh ken, buka oman lhe that manteng"

'Tetap dibawah bantal, saya kalok pun ada tidak saya pegang kan, bukak oamn masih banyak kok'

Af : :Gop kacok ka kokang katimbak aju”

'Orang kamu ambel kamu kokang kamu tembak teros'

Pada percakapan tersebut terjadi campur kode bahasa Aceh dengan bahasa Indonesia. "Gajian ngen bang reja ijok?" pada kalimat tersebut terdapat campur kode antara bahasa Aceh dengan bahasa Indonesia. Seperti kata gajian dan kata bang dalam kalimat tersebut menggunakan bahasa Indonesia. Pada kalimat lain juga terdapat campur kode antara bahasa Aceh dengan bahasa Indonesia seperti pada kalimat Tetap iminyub bantal, ike adak na pih hana ta sentuh ken, buka oman lhe that manteng" yang diucapkan oleh Safrizal ada kata tetap dan kata bantal yang disisipkan. Hal tersebut terjadi agar komunikasi yang terjalin tetap terlihat akrab dan untuk menggantikan kosakata yang terlalu panjang dalam bahasa Aceh seperti kata gajian.

Data 2 


\section{2) Hari / Tanggal Oktober 2020}

Pukul

WIB

$\begin{aligned} & \text { Tempat } \\ & \text { Nama Informan }\end{aligned}$ : Lingkungan 4
Pembeli 1 Sittah dan Ron
: "Ini udah dibelah
buk."
Pedagang $\quad$ : "Dah dibelah"
Pembeli $1 \quad$ : "Ikan ada bu?"
Pedagang $\quad \begin{gathered}\text { : "Cok udeng } \\ \text { manteng" } \\ \text { "Ambel udang } \\ \text { saja' }\end{gathered}$

Pembeli 1 : "Haek, yang ini berapa nie?"

'Tidak, yang ini berapa nie?'

\section{Pedagang : : "Itu 15 ada."}

Dalam peristiwa tutur berikut terdapat alih kode, yaitu pencampuran bahasa Indonesia dengan bahasa Indonesia. Ketika pedagang mengatakan bahwa pembeli mengambil udang saja, pembeli langsung menjawab "Haek, yang ini berapa nie?" yang artinya tidak mau, yang ini berapa. Pada kalimat tersebut pembeli menyisipkan kata Haek dalam tuturannya karena kata tersebut merupakan kata yang sering disebutkan dalam masyarakat dan banyak dimengerti oleh masyarakat yang bukan penutur asli Aceh. Percakapan ini memiliki maksud yaitu pembeli menanyakan ikan, namun pedagang menawarkan udang. Sehingga komunikasi yang berlangsung menjadi lebih akrab dan dapat dipahami oleh keduanya.

Data 3

3) Hari / Tanggal : Senin, 07 Desember 2020

Pukul : 17.00 WIB s.d. 16.20

WIB

Tempat
$\mathrm{Sz} \quad$ : "Kok lucu eeeeu"

: 'kok lucu iyaa'

$\mathrm{Nz} \quad$ : "Luculah menye hanjeut nyan sikureng lapan lahee"

: 'Lucu lah kalau tidak bisa itu sembilan delapan'

Jm : "sembilan delapan"

$\mathrm{Nz} \quad$ : "Eeeeu"

: 'Iyaa'

Jm : : "Bukan 95 bukan 94"

$\mathrm{Sz} \quad$ : "Lucu kali dia"

$\mathrm{Nz} \quad$ : "Hadeuh, udah nasipnya"

: 'Aduh, udah nasipnya'

$\mathrm{Sz} \quad$ : "Nasep, gak mau nie belajar, gitulah bukan kerja di grosir kek tu gak bisa dia kerja kek orang kayak dia. Kacok nyoe ile, peu yue cok nyoe heheeh haek tatemanyeng hehehe gak mau kita bertanya pun setiap hari."

: 'Nasip, gak mau nie belajar, gitulah kerja di grosir kek tu gak bisa dia kerja kek orang kayak dia. Kamu ambil ini dulu, apa disuruh ambil ini hehehe tidak mau bertanya hehehe gak mau kita bertanya setiap hari.'

Jm : "Iya" 
$\mathrm{Sz} \quad$ : "Lam kacok nyoe ilee, bodoh nantik dia."

: 'Didalam kamu ambil ini dulu, bodoh nantik dia.'

Pada data tersebut terdapat campur kode bahasa Indonesia dengan bahasa Aceh. Nasep, gak mau nie belajar, gitulah bukan kerja di grosir kek tu gak bisa dia kerja kek orang kayak dia. Kacok nyoe ile, peu yue cok nyoe heheeh haek tatemanyeng hehehe gak mau kita bertanya pun setiap hari." Pada kutipan percakapan tersebut terdapat dua bahasa yaitu bahasa Aceh dan bahasa Indonesia. Penutur menyisipkan kalimat Kacok nyoe ile, peu yue cok nyoe heheeh haek tatemanyeng dalam tuturannya yang artinya Kamu ambil ini dulu, apa disuruh ambil ini hehehe tidak mau bertanya. Sehingga terjadilah campur kode dalam tuturan tersebut. kalimat lain dalam peristiwa tutur tersebut yaitu "Lam kacok nyoe ilee, bodoh nantik dia." Pada kalimat tersebut juga terdapat dua bahasa yaitu bahasa Aceh dan Indonesia. Hal tersebut terjadi karena sudah ada hubungan yang akrab diantara keduanya, sehingga walaupun bahasa yang digunakan tidak satu, lawan tutur tetap mengerti dengan apa yang dimaksud oleh penutur.

Data 4

4) Hari / Tanggal : Senin, 21 Desember 2020

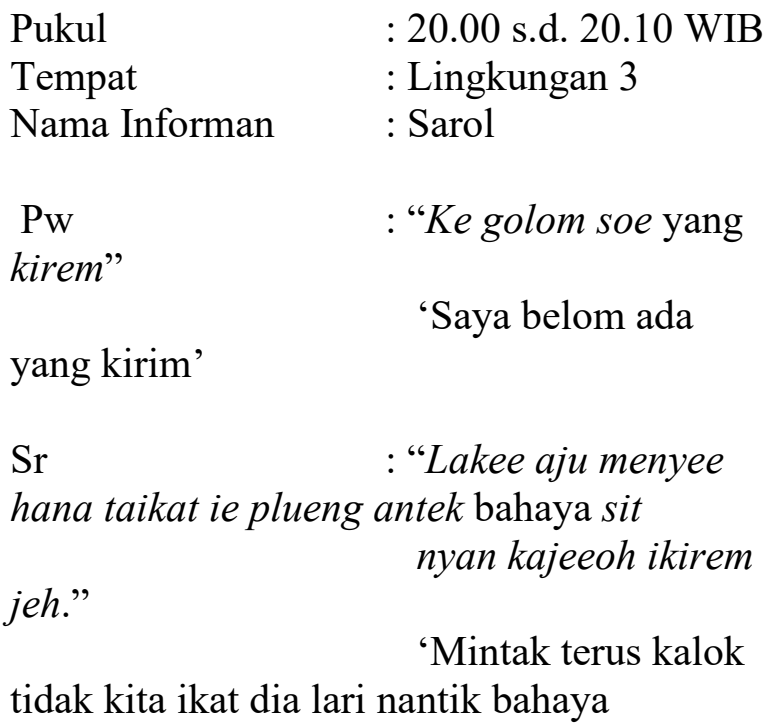
dia kirem’
jugak itu udah jauh
G1

$$
\begin{aligned}
& \text { : "Heuh" } \\
& \text { 'Huh' }
\end{aligned}
$$
Gl
: "Cok hp kah"
'Ambil hp kamu'
$\mathrm{Sr}$
: "Cas ile long yak

meen mobile legen le ken yan lam ulee"

'Cas dulu saya mau

main mobile legen dulu bukan itu dalam pikiran'
$\mathrm{Pt}$
: "Hana lee kaa
abeuh"
abis'
$\mathrm{Pw}$
: "Kaa abeuh"
'Udah abis'

'Tidak ada lagi udah

Campur kode yang terdapat pada data tersebut yaitu campur kode bahasa Aceh dengan bahasa Indonesia. Suwandi (dalam Rulyandi, 2014:29) menerangkan bahwa campur kode adalah "penggunaan dua bahasa atau lebih atau ragam bahasa secara santai antara orangorang yang kita kenal dengan akrab. Dalam situasi berbahasa yang informal ini, dapat dengan bebas mencampur kode, khususnya apabila ada istilah-istilah yang tidak dapat diungkapkan dalam bahasa lain." Dalam percakapan tersebut, bahasa yang dominan digunakan penutur adalah bahasa Aceh, namun ada beberapa kosakata yang menggunakan bahasa Indonesia, seperti kata bahaya dan cas. Hal tersebut terjadi karena bahasa Aceh bahaya dan cas sama seperti yang ada pada bahasa Indonesia. Sehingga terjadilah campur kode dalam percakapan tersebut.

\section{Data 5}

5) Hari / Tanggal : Senin, 21 Desember 2020

Pukul

Tempat
: 21.30 s.d. $21.45 \mathrm{WIB}$

: Lingkungan 3 
November 2020

$\begin{array}{ll}\text { Nama Informan } & \text { : Patur } \\ \mathrm{Pt} & \text { : "Nyan poh rol" } \\ & \text { 'Itu pukul rol' } \\ \mathrm{Sr} & \text { : "Dua ule nyoe" } \\ & \text { 'Dua kepala ini' } \\ \mathrm{Pt} & \text { : "Kapoeh ju, poh ju" } \\ \mathrm{pukul} \text { terus' } & \text { 'Kamu pukul terus, } \\ \mathrm{Sr} & \text { : "Sabar lah" } \\ \mathrm{Pt} & \text { : "Aaa, trep that kah" } \\ \mathrm{kamu} & \text { 'Aaa, lama kali }\end{array}$

$\mathrm{Sr}$

behee"

behee'

: “Alah meen plueng

'Alah mainnya lari

$\mathrm{Pt}$

: "Kaleet"

'Kamu kejar'

Sr
songket hoe"

angkat mana'

: "Songket, tukang

'Angkat, tukang

$\begin{array}{ll}\text { Gl } & \text { : "Ka pike ke zilong } \\ \text { zah" } & \text { 'Kamu pikir saya }\end{array}$

$\mathrm{Pt}$

: “Ooomak kop saket

sakit aah'

'Ooomak cukup

bahasa Indonesia. Bahasa utama yang digunakan penutur adalah bahasa Aceh, namun penutur juga menyisipkan kata dalam bahasa Indonesia seperti kata dua, sabar, tukang, dan hajar. Sehingga terjadi campur kode dalam peristiwa tutur tersebut. hal tersebut terjadi karena kosakata yang dipakai sama dengan bahasa Indonesia, seperti kata dua dalam bahasa Aceh juga dua. Hal lain yang menyebabkan campur kode tersebut yaitu karena penutur mencari kosa kata yang mudah untuk diucapkan.

Data 6

6) Waktu : Sabtu, 24 Oktober 2020

Pukul : 08.00 WIB s.d. 08.27

WIB

Tempat : Lingkungan 3

Nama Informan : Mami

Penjual : "Ini bukan lontong biasa."

Pembeli 1 : "Iya”

Penjual : "Luar biasa"

Pembeli 2 : "Iya gak tau mami, pasti pigi dia yang tau mami pasti ketawain aja kan mi"

Penjual : "Iya, pigi-pigi lah gak pusing aku"

Pembeli 2 : "Aku gak manggel padan kok hehheh"

'Aku gak... manggel kok hehheh'

Penjual : "Hehm kue kan kalok dijawa tak orang tu capek dia, hiyaa"

'Hehm kamu kan kalok di Jawa tak orang tu capek dia, hiyaa'

Dalam percakapan tersebut terdapat campur kode yaitu campur ode bahasa Aceh dengan 

Pembeli 2 : "Kalok disana ini
kali ya"

Penjual

: "Pak lurah aja
jarang yang jalan
kaki"

Data 7

7) Hari / Tanggal : Senin, 21

Pukul

: 20.00 s.d. $20.40 \mathrm{WIB}$

Tempat : Lingkungan 3

Nama Informan : Zikri

$\mathrm{Sr}$

: "Hek ke peugeut ie

peugadeuh rusli abadi abadai"

'Capek saya buat di

iliangin sama rusli abadi abadai'

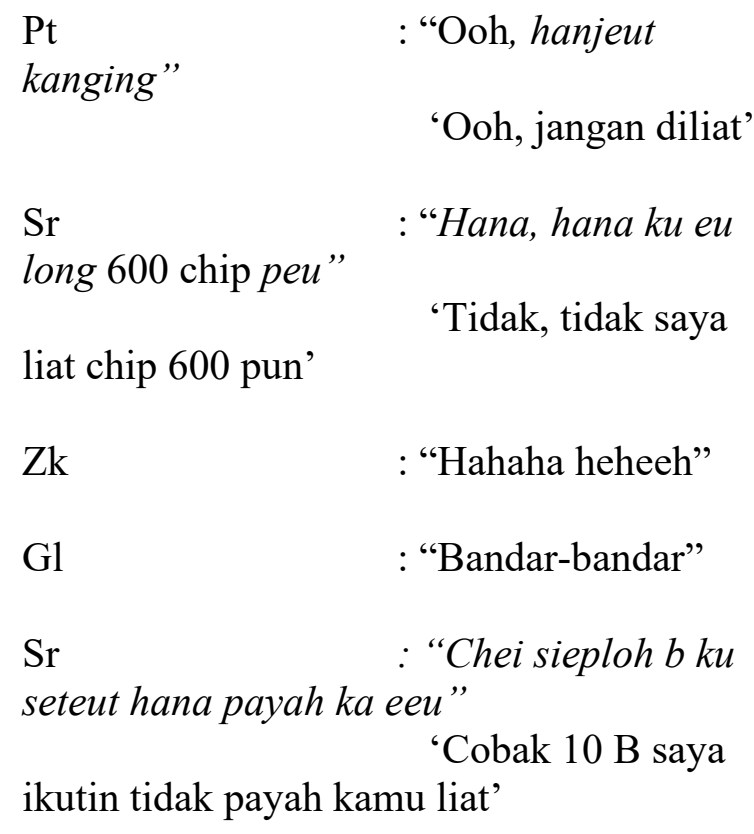

$\mathrm{Ag}$

: "Seutout rumoh tur

olah-olah"

olah-olah'

$\mathrm{Pt} \quad$ : "Oke"

Pw

'Ikut kerumah tur

: "Ooo ke golom"

'Ooo saya belum'
$\mathrm{Sr}$

pak wan"

selow pak wan'

$\operatorname{Pr}$

top ap pak wan"

up pak wan'

: "Ooo roneh selo-selo

'Ooo anda selow-

: "Yang kaleuh neu

'Yang sudah di top

$\mathrm{Pw}$

kirem"

yang kirim'

: "Ke golom soe yang

'Saya belom ada

Pada percakapan tersebut terjadi campur kode dalam bahasa Aceh, Indonesia dan Inggris. Percakapan yang terjadi membahas seputar permainan yang mereka mainkan sebagai anak muda. Pada dasarnya pemuda tersebut menggunakan bahasa Aceh sebagai bahasa utamanya, namun mereka juga menyisipkan bahasa Indonesia dan bahasa asing dalam tuturannya. Kosakata asing yang digunakan dalam percakapan tersebut seperti chip dan top up. Sedangkan kosakata bahasa Indonesia yang digunakan yaitu kata yang, olah dan bandar. Karena adanyadua bahasa yang digunakan dalam satu kalimat oleh penutur maka terjadilah campur kode. Hal tersebut terjadi karena seperti kosa kata bahasa inggris merupakan kosakata yang digunakan dalam penyebutan istilah-istilah permainan tersebut sehingga penutur terbiasa menggunakan kosa kata tersebut. sementara untuk kosa kata bahasa Indonesia karena penutur tidak menemukan padanan kata dalam bahasa Aceh sendiri.

Data 8

8) Hari / Tanggal : Senin, 10 Oktober 2020

Pukul : 21.00 WIB s.d. 21.40

WIB

Tempat : Lingkungan 3

Nama Informan : Safrizal 
$\mathrm{Sz}$ : "Kadang-kadang bak ta mimbak"

'Kadang-kadang kalok kita tembak'

$\mathrm{Nz} \quad$ : "Tekepak lh"

'Terkejut lah'

Af : "Jangan bob"

$\mathrm{Sz} \quad$ : "Meno ee, exxzz... goyang wak nyan"

'Gini ee, exxzz... takut orang itu'

Af : "Purak-purak wewen kah"

'purak-purak wewen kamu'

$\mathrm{Sz}:$ "Eeeuh evolusien manteng eun omah wa bak tek peduk aju ateh nyoe hoe laen hehehe, pedul adu ateh hoe laen mek euno, hahaahh. wak nyoe tanyeng ada liat rokok hana tanyengtanyeng aman, rukok bie ke ke maknum nyan peduk hinan aman, pokok jih hana putoh long rukok asai ka bengeh kana rukok ke"

'Eeeuh evolution masih ada dua batang lagi taruk terus atas sini kemana lagi hehehe.. orang ini tidak ada bertanya-tanya ada liat rokok aman, rokok maknum itu mintak untuk saya, saya taruk disitu. Pokoknya tidak pernah putus saya rokok asal udah pagi udah ada saya rokok.'
Pada percakapan tersebut terdapat campur kode dalam bahasa Aceh, Indonesia dan asing. Bahasa dasar yang digunakan oleh penutur adalah bahasa Aceh, namun penutur juga menyelipkan bahasa indonesia dan bahasa Asing dalam tuturannya. Seperti pada kalimat "Eeeuh evolution manteng eun omah wa bak tek peduk aju ateh nyoe hoe laen hehehe, pedul adu ateh hoe laen mek euno, hahaahh.. wak nyoe tanyeng ada liat rokok hana tanyeng-tanyeng aman, rukok bie ke ke maknum nyan peduk hinan aman, pokok jih hana putoh long rukok asai ka bengeh kana rukok ke" bada tuturan tersebut penutur menyisipkan bahasa asing yaitu kata evolution yang merupakan salah satu merek rokok sehingga kata tersebut tidak ada padanannya dalam bahasa Aceh. Kata lain yang bukan bahasa Aceh yaitu kadangkadang dan goyang yang juga digunakan oleh salah seorang penutur sehingga mengakibatkan terjadinya campur kode dalam peristiwa tutur tersebut.

Data 9

9) Hari / Tanggal : Senin, 21 Desember 2020

Pukul : 20.00 s.d. 20.10 WIB

Tempat : Lingkungan 3

Nama Informan : Angga

$\mathrm{Ag}$

: "Sie zilong hero

eeeu"

'Si zilong hero iya'

$\operatorname{Pr}$

: "Abeh-abeh"

'Abis-abis'

$\mathrm{Pt}$

hoe ipoh"

kemana dia pukul'

'Hero MM itu, ih

Ag : "Pus-pus"

$\mathrm{Sr}$

na yoe aaa, lah na ke" 
'Selow mana yang pus ada ini aaa, untung ada saya'

$\operatorname{Pr} \quad$ : "Pue nyan-pue nyan"

Pt : "Maju rol, maju"

$\mathrm{Ag} \quad$ : "Santai-santai

mandum, serah kan bak sarol"

semua, kasih kan sama sarol'

'Santai-santai

$\begin{array}{ll}\mathrm{Pt} & : \text { "Kah rol MPV" } \\ \text { pemenangnya' } & \\ \mathrm{Sr} & \text { : "Tamu rol } \\ & \text { 'Mana-mana-mana' } \\ \mathrm{Pt} & \text { : "Bek rol matee kah" } \\ & \text { 'Jangan rol mati }\end{array}$

kamu’

$\begin{array}{ll}\mathrm{Ag} & \text { : “Ooop" } \\ \mathrm{Sr} & \text { : 'Kaa" } \\ & \text { 'Udah' } \\ \mathrm{Ag} & \text { : "Ka pus aju nyoe" } \\ & \text { 'Kamu pus terus itu' } \\ \mathrm{Sr} & \text { : "Mundor lee nyoe } \\ \text { bagah that menang" } & \text { 'Mundur dulu ini }\end{array}$

cepat kali menangnya'

\begin{tabular}{|c|c|}
\hline $\mathrm{Ag}$ & . "Rak sampeng- \\
\hline sampeng" & \\
\hline samping, & 'Dari samping- \\
\hline $\begin{array}{l}\mathrm{Pr} \\
\text { hahaha" } \\
\text { 'Cepat ka }\end{array}$ & $\begin{array}{l}\text { : "Bagah that menang } \\
\text { ahaha' }\end{array}$ \\
\hline
\end{tabular}

Pada percakapan tersebut terdapat campur kode dalam bahasa Aceh, Indonesia dan asing. Bahasa yang dominan digunakan adalah bahasa Aceh hal tersebut dapat dilihat dari kosakata yang dominan digunakan oleh penutur. Dalam percakapan yang berlangsung, selain bahasa Aceh yang memang dominan digunakan oleh penutur, penutur juga menyispkan bahasa Indonesia dan bahasa asing dalam tuturannya. Seperti pada kalimat "Sie zilong hero eeeu" penutur menggunakan kosakata asing yaitu pada kata hero yang dalam bahasa Indonesia disebut dengan jagoan. Kosakata tersebut digunakan oleh penutur karena kosakata tersebut merupakan yang sering digunakan dalam permainan sehingga penutur terbiasa menyebutkan hero. Kosakata dalam bahasa Indonesiajuga ada yang disisipkan yaitu seperti kata maju, serahan, dan menang. Sehingga dalam peristiwa tersebut terjadi campur kode karena dalam setiap kalimat yang diucapkan oleh penutur memiliki dua bahasa atau lebih.

Data 10

10) Waktu : Sabtu, 24 Oktober 2020

Pukul :08.00 WIB s.d. 08.27

WIB

Tempat : Lingkungan 3

Nama Informan $\quad$ : Mami

An

makan kangkong?"

: “Gakngantok ke

'Gak ngantuk kau makan kangkung?'

$\mathrm{Tt}$

: "Enggak"

$\mathrm{Ai}$

: "Lah jadi opo?"

'Lah, jadi apa?'

$\mathrm{Tt}$

seee"

: "Telponan dia eee

$\mathrm{Nn}$

: "Eeee hahahaah"

Pada percakapan tersebut terdapat campur kode yaitu campur kode bahasa Indonesia dengan bahasa Jawa. Pada kalimat "Lah jadi opo?" penutur menggunakan dua bahasa yaitu 
bahasa Indonesia yang disisipkan bahasa Jawa yaitu kata opo yang artinya apa. Sehingga dalam peristiwa tutur tersebut terjadi campur kode.

\section{Simpulan dan Saran}

Masyarakat yang multibahasa muncul karena masyarakat tutur tersebut mempunyai atau menguasai lebih dari satu varian bahasa yang berbeda-beda. Sehingga mereka dapat menggunakan pilihan bahasa tersebut dalam kegiatan komunikasi. Varian bahasa yang terdapat pada masyarakat Matang Seulimeng Kota Langsa dari hasil penelitian yang dilakukan terdapat 8 bentuk varian alih kode dan 10 bentuk varian campur kode. Data tersebut ada yang menggunakan bahasa Aceh, bahasa Indonesia, bahasa Jawa, dan bahasa asing. Seperti salah satu data yang diperoleh yaitu pada data (1) yang menggunakan bahasa Aceh dan juga bahasa Indonesia.

Alih kode dan campur kode yang terjadi di masyarakat Gampong Matang Seulimeng, Kota Langsa karena adanya situasi berbahasa yang beragam, penutur yang heterogen, tidakadanya padanan kosakata dalam satu bahasa, kebiasaan, dan juga agar terlihat lebih gaul oleh lawan tuturnya sehingga terjadilah alih kode dan campur kode tersebut. 


\section{Daftar Referensi}

Abdul Chaer. 2006. Tatat Bahasa Praktis Bahasa Indonesia. Jakarta: PT Rineka Cipta.

Abdul Chaer. 2010. Sosiolinguistik Perkenalan Awal. Jakarta: Rineka Cipta.

Arikunto, Suharsimi. 2018. Prosedur Penelitian Suatu Pendekatan Praktik. Jakarta: PT. Rineka Cipta.

Azwardi. 2018. Metode Penelitian Pendidikan dan Sastra Indonesia. Banda Aceh: Syiah Kuala University Press.

Badan Pengembangan dan Pembinaan Bahasa. 2017. Kamus Besar Bahasa Indonesia Edisi Kelima. Jakarta: Badan Pengembangan dan Pembinaan Bahasa.

Chaer, Abdul dan Agustina, L. 2004. Sosiolinguistik: Perkenalan Awal. Jakarta: Rinneka Cipta.

Chaer, Abdul dan Leonie Agustina. 2017. Sosiolinguistik Perkenalan Awal. Jakarta: Rinneka Cipta.

Marni, Wa ode. 2016. Campur Kode dan Alih Kode dalam Peristiwa Jual Beli di Pasar Labuan Tabelo Kecamatan Warkorumba Utara Kabupaten Buton Utara. Jurnal Bastra, 2(1).

Moleong. 2017. Metode Penelitian Kualitatif. Bandung: PT. Remaja Rosdakarya.

Sugiyono. 2016. Metode Penelitian Kuantitatif, Kualitatif, R\&D. Bandung: CV Alfabeta 